\title{
RECURSOS EDUCACIONAIS ABERTOS (REA) COM PESQUISA E INOVAÇÃO RESPONSÁVEIS (RRI) PARA A PRODUÇÃO DE CONHECIMENTO EM POLÍTICAS EDUCACIONAIS: O CASO DO MESTRADO PROFISSIONAL EM GESTÃO E AVALIAÇÃO DA EDUCAÇÃO PÚBLICA DA UNIVERSIDADE FEDERAL DE JUIZ DE FORA (UFJF)
}

BORGES, Eliane Medeiros ${ }^{1}$

SANABIO, Marcos Tanure ${ }^{2}$

MAGALDI, Juliana Alves ${ }^{3}$

\begin{abstract}
RESUMO
O trabalho propõe a análise e discussão sobre a utilização de Recursos Educacionais Abertos (REA) no Mestrado Profissional em Gestão e Avaliação da Educação Pública da Universidade Federal de Juiz de Fora (UFJF), como demonstração da viabilidade da interação de variadas mídias e recursos online no processo educacional, por meio dos quais alunos do Programa realizaram suas atividades e promoveram interações, tendo como referência sobre a aplicabilidade dos REA nos estudos de Okada, Amiel, Nobre, Mallmann e Mendes. Este estudo exploratório reflete sobre como utilizar os REAs (mapas do LiteMap) como práticas pedagógicas ditas inovadoras, em contexto de cursos superiores. A metodologia tem como base o conceito de pesquisa e inovação responsáveis (RRI) com as seguintes etapas: uso de REA, adaptação da prática pedagógica e transformação do ensino-aprendizagem do projeto Europeu Engage que promoveu a plataforma LiteMap para formação de educadores para RRI. São apresentadas duas experiências de atividades no Mestrado Profissional, com a utilização de REA, seu desenvolvimento e análise, sendo a primeira na Disciplina de Administração e Financiamento da Educação Pública e a segunda nas atividades de Qualificação dos mestrandos, em 2017 e 2018 . Ambas as experiências, desenvolvidas de modo experimental, foram exitosas e se demonstraram oportunas para sua disseminação em todo o Programa de Pós-Graduação. Os resultados deste estudo sugerem que REA com LiteMap podem ser utilizados, adaptados e transformados num processo pedagógico que reúne conteúdos e métodos, como conhecimento construído nos mapas.
\end{abstract}

PALAVRAS-CHAVES: REA; Mapas conceituais; Produção de conhecimento; Educação Pública; Educação; RRI.

\footnotetext{
${ }^{1}$ Doutora em Educação (UNICAMP). Professora Associada da Faculdade de Educação da Universidade Federal de Juiz de Fora. Líder do grupo Educação, Cultura e Comunicação (EDUCCO). Coordenadora do Mestrado Profissional em Gestão e Avaliação da Educação Pública (PPGP/UFJF). Coordenadora UAB/UFJF. E-mail: mborges.eliane@gmail.com

${ }^{2}$ Doutor em Administração (UFLA). Professor Titular da Faculdade de Administração e Ciências Contábeis e Pró-Reitor de Infraestrutura e Gestão da Universidade Federal de Juiz de Fora. Membro do Comitê Gestor Nacional do Mestrado Profissional em Administração Pública (PROFIA/ANDIFES). E-mail: mtanure.sanabio@ufjf.edu.br

${ }^{3}$ Doutora em Ciência da Religião (UFJF). Coordenadora do Núcleo de dissertação do Mestrado Profissional em Gestão e Avaliação da Educação Pública (PPGP/UFJF). E-mail: jmagaldi @ caed.ufjf.br
} 


\title{
$e$-Curriculum
}

OPEN EDUCATIONAL RESOURCES (OER) WITH RESPONSIBLE RESEARCH AND

INNOVATION (RRI) FOR THE PRODUCTION OF KNOWLEDGE IN EDUCATIONAL

POLICIES: THE CASE OF THE PROFESSIONAL MASTER IN MANAGEMENT AND

ASSESSMENT OF PUBLIC EDUCATION AT THE JUIZ DE FORA FEDERAL UNIVERSITY

(UFJF)

BORGES, Eliane Medeiros ${ }^{4}$
SANABIO, Marcos Tanure
MAGALDI, Juliana Alves

\begin{abstract}
This work proposes the analysis and discussion about the use of Open Educational Resources (OER) in the Professional Master in Management and Assessement of Public Education at the Juiz de Fora Federal University (UFJF), as a demonstration of the viability of the interaction of various media and online resources in the educational process. through which the students of the Program carried out their activities and promoted interactions. The conceptual and theoretical contributions of Okada, Amiel, Nobre, Mallmann and Mendes are used. This exploratory study examines how to make REA (Litemap maps) become innovative pedagogical practices, for example, in undergraduate or masters courses, in face-to-face or distance education. The methodology is based on responsible research and innovation (RRI) with the following steps: use of OER, adaptation of pedagogical practice and transformation of teaching learning, from the European ENGAGE project that promoted the LiteMap platform for training educators for RRI. Two experiences of activities in the Professional Masters are presented, with the use of OER, its development and analysis, being the first in the Public Education Administration and Financing Course and the second in the Qualification activities of the masters in 2017 and 2018. Both the experiments, were successful and were shown to be appropriate for their dissemination throughout the Postgraduate Program. The results of this study suggest that REA with LiteMap can be used, adapted and transformed in an interwoven process between maps mapped knowledge and transforming practices with mapping process.
\end{abstract}

KEYWORDS: REA; Conceptual maps; Knowledge production; Public education; Education; RRI.

\footnotetext{
${ }^{4}$ PhD in Education (UNICAMP). Associate Professor at the Faculty of Education of the Federal University of Juiz de Fora. Leader of the group Education, Culture and Communication (EDUCCO). Coordinator of the Professional Master in Management and Evaluation of Public Education (PPGP / UFJF). Coordinator UAB/ UFJF.E-mail: mborges.eliane@gmail.com

${ }^{5}$ Doctor of Business Administration (UFLA). Full Professor of the Faculty of Administration and Accounting Sciences and Pro-Rector of Infrastructure and Management at the Federal University of Juiz de Fora. Member of the National Management Committee of the Professional Master in Public Administration (PROFIA/ ANDIFES).E-mail: mtanure.sanabio@ufif.edu.br

${ }^{6}$ PhD in Religious Science (UFJF). Coordinator of the Dissertation Nucleus of the Professional Master in Management and Evaluation of Public Education (PPGP / UFJF).E-mail: jmagaldi@caed.ufjf.br
}

Eliane Medeiros BORGES, Marcos Tanure SANABIO, Juliana Alves Magaldi Recursos educacionais abertos (REA) com pesquisa e inovação responsáveis (RRI) para a produção de conhecimento em políticas educacionais: o caso do mestrado profissional em gestão e avaliação da educação pública da Universidade Federal de Juiz de Fora (UFJF) 


\section{INTRODUÇÃO}

Embora a relação entre tecnologias e processos educativos tenha suas origens muito antes da existência das Tecnologias da Informação e da Comunicação (TIC) é após seu surgimento e, em particular, seu desenvolvimento nas últimas décadas, que esta relação se torna mais intensa, no mesmo contexto em que as tecnologias assumem um lugar central no sistema produtivo das sociedades. Neste sentido, Castells aponta que

[...] no final do século $\mathrm{XX}$, vivemos um desses raros intervalos na história. Um intervalo cuja característica é a transformação de nossa "cultura material" pelos mecanismos de um novo paradigma tecnológico que se organiza em torno da tecnologia da informação (CASTELLS, 2005, p. 67).

Embora o conceito de tecnologia tenha múltiplos significados e algumas controvérsias, pode-se convergir para o entendimento de que "Computadores, sistemas de comunicação, decodificação e programação genética são todos amplificadores e extensões da mente humana" (CASTELLS, 2005, p. 69).

Como expressão dessa relação constituída entre Educação e TIC na contemporaneidade, pode-se apontar a intensificação da exploração da potencialidade da Educação a Distância, entendida como processo educativo no qual professor e estudante se utilizam de comunicação mediada por tecnologias, na medida em que se encontram separados espacial ou temporalmente.

Neste sentido, e no contexto da EAD, nota-se uma tendência à criação de políticas que, "voltando-se para a maior democratização do acesso à educação no ensino superior, objetivam atender às exigências atuais de profissionais multifuncionais, polivalentes, inovadores e ambiciosos de uma formação continuada" (BLIKSTEIN E ZUFFO, 2006, p. 31). Peters, por sua vez, propõe a flexibilização do ensino superior, pela adaptação "aos novos requisitos da vida em uma sociedade do conhecimento pós-industrial, pós-moderna: que pedem formas de ensinar que sejam mais flexíveis" (PETERS, 2002, p. 237).

É neste contexto de transformações e uso intensificado de TIC que se localiza o caso do Mestrado Profissional em Gestão e Avaliação da Educação Pública da Universidade Federal de Juiz de Fora (UFJF). De criação pioneira no país, o Mestrado Profissional tem utilizado, nas disciplinas e na orientação de elaboração de dissertações, recursos de Ambiente Virtual de Aprendizagem (AVA) e outros meios tecnológicos para realizar a formação de seus estudantes. Continuando seu movimento no sentido de inovações pedagógicas, avançou, 
Programa de Pós-Graduação em Educação: Currículo

recentemente, para a introdução de Recursos Educacionais Abertos (REA), num esforço de entendimento e aplicação do potencial do uso de tecnologias no interior dos seus processos de ensino e aprendizagem.

Os REA "são materiais para ensinar, aprender e pesquisar, que estão em domínio público ou são publicados com licença de propriedade intelectual que permita sua livre utilização, adaptação e distribuição", conforme conceituação da Unesco ${ }^{7}$. Considerando-se o surgimento de produção e integração dos REA à Educação, pode-se entender como pertinente o estudo sobre os modos a partir dos quais esses recursos podem se constituir em práticas pedagógicas ditas inovadoras, por exemplo, em cursos de graduação ou de Mestrado, presenciais ou a distância.

Este trabalho trata de reflexões sobre esta nova estratégia pedagógica em curso no Mestrado Profissional, por meio da apresentação de seu uso e de seus resultados. Nesse sentido, propõe análise e discussão sobre a utilização de Recursos Educacionais Abertos (REA) como demonstração da viabilidade da interação de variadas mídias e recursos on-line no processo educacional, por meio dos quais alunos do Programa, dispersados espacialmente, realizaram suas atividades e promoveram interações. Pretende-se, com este estudo, contribuir para o avanço das discussões nesse campo específico e, ao mesmo tempo, disponibilizar experiências concretas que avaliem os potenciais e eventuais limites dessa nova tecnologia de ensino.

\section{RECURSOS EDUCACIONAIS ABERTOS (REA) NO MESTRADO PROFISSIONAL EM GESTÃO E AVALIAÇÃO DA EDUCAÇÃO PÚBLICA}

Pereira et al. (2016) trazem uma discussão interessante sobre a natureza dos REA. Serão eles, na ótica dos autores, materiais didáticos ou recursos educacionais? Ao mencionarem Allen e Seaman $(2014)^{8}$, em pesquisa no meio acadêmico, fica evidenciada uma relativa confusão do conceito, de REA com recursos livres e gratuitos ou, mesmo, open source (código aberto), numa alusão ao software livre. Contudo, afirmam que os REA são

\footnotetext{
${ }^{7}$ Disponível em: <http://www.unesco.org/new/pt/brasilia/communication-and-information/access-toknowledge/ict-in-education/open-educational-resources/>. Acesso em: 24 abr. 2018.

${ }^{8}$ ALLEN, I. E; SEAMAN J. 2014. Opening the Curriculum: Open Educational Resources in U.S. Higher Education Babson Survey Research Group.
}

Eliane Medeiros BORGES, Marcos Tanure SANABIO, Juliana Alves Magaldi Recursos educacionais abertos (REA) com pesquisa e inovacão responsáveis (RRI) para a produção de conhecimento em políticas educacionais: o caso do mestrado profissional em gestão e avaliação da educação pública da Universidade Federal de Juiz de Fora (UFJF) 
Programa de Pós-Graduação em Educação: Currículo

"materiais educacionais multiformes, com potencialidades para os multiletramentos e para os processos de ensino e de aprendizagem em espaços formais (em todos os níveis de ensino) e não formais" (PEREIRA et al., 2016, p. 465), para uso no desenvolvimento e prática do conhecimento, de modo aberto e amplo para reconfigurações, refino e aprimoramento.

Okada (2011) se coloca na mesma perspectiva, ao considerar que os Recursos Educacionais Abertos são instrumentos do processo de ensino-aprendizagem na era digital, nos quais é possível aos seus participantes um processo de construção do conhecimento colaborativo e aberto, a partir de interações intensivas e permanentes.

Ainda, neste sentido conceitual, Pretto (2010) e Amiel (2012) afirmam que os REAamplificam o processo de ensino-aprendizagem dos seus atores, por suas características de ser abertos e legais (no sentido de estarem disponíveis para todos), privilegiando a colaboração na construção coletiva do conhecimento que, por seu turno, seria transformadora.

Para Torres et al. (2017, p. 1.537), a amplitude da utilização dos REA na educação concede a "possibilidade de desenvolver objetos de aprendizagens, recursos midiáticos ou mesmo ferramentas capazes de ampliar o acesso a um processo de ensino-aprendizagem de maior qualidade".

Vale ressaltar que o conceito de REA sofreu e sofre evoluções, como disposto no Quadro 1:

Quadro 1: REA: Conceitos e concepções

\begin{tabular}{|l|l|}
\hline \multicolumn{1}{|c|}{ Instituição } & \multicolumn{1}{|c|}{ Conceito } \\
\hline Unesco (2002) & $\begin{array}{l}\text { Recursos ou técnicas abertas e de domínio } \\
\text { público para utilização e modificação de } \\
\text { terceiros e participantes. }\end{array}$ \\
\hline $\begin{array}{l}\text { Definição de Recurso Educacional Aberto } \\
\text { (REA) resultante do texto da Unesco/Common } \\
\text { wealth of Learning (2011) }\end{array}$ & $\begin{array}{l}\text { Similar ao entendimento da Unesco (2002), } \\
\text { pois admite os REA como material de ensino- } \\
\text { aprendizagem licenciado, de domínio público } \\
\text { e aberto que poderá ser utilizado e adaptado } \\
\text { por todos que o acessam. }\end{array}$ \\
\hline
\end{tabular}




\begin{tabular}{|l|l|}
\hline $\begin{array}{l}\text { Declaração de Paris sobre Recursos } \\
\text { Educacionais Abertos (2012) }\end{array}$ & $\begin{array}{l}\text { Na Declaração de Paris sobre REA, em 2012, } \\
\text { permanecem as questões de recursos de } \\
\text { ensino-aprendizagem, licenciados, de domínio } \\
\text { público e abertos, com um detalhe - a ênfase } \\
\text { nos direitos de propriedade intelectual e do } \\
\text { respeito da propriedade do material e obra. }\end{array}$ \\
\hline REA nas pesquisas atuais & $\begin{array}{l}\text { Aqui é reforçada a questão da propriedade } \\
\text { intelectual e sua maleabilidade na publicação } \\
\text { aberta, de mídias e outras tecnologias de } \\
\text { difusão, construção e reconstrução do } \\
\text { conhecimento, com componente dos 4Rs: } \\
\text { revisar, reusar, remixar e redistribuir. }\end{array}$ \\
\hline
\end{tabular}

Fonte: Adaptado de Torres et al., 2017, p. 1.537-1.338

A propósito da questão apresentada na introdução deste trabalho, sobre a pertinência da reflexão sobre o aspecto inovador da dimensão pedagógica dos REA, Nobre et al. (2015) trazem um reflexão consistente sobre os ciclos de design, implementação e avaliação da metodologia dos cursos on-line da Universidade Aberta de Portugal. Os autores cunharam uma terminologia de Práticas Educacionais Abertas (PEA) mediadas pelos REA que são, em tese, "participação ativa nas interações colaborativas em virtude das nuances psicológicas e sociológicas, das implicações económicas e culturais, da mediação tecnológica, em redes livres e abertas no âmbito da pedagogia flexível e aberta" (NOBREet al., 2015, p. 256). Dessa forma, ao utilizar as PEA mediadas por REA, obtém-se contemporaneidade e inovação nos desenhos didáticos e pedagógicos dos cursos.

No contexto desafiador do ensino superior a distância, as PEA, mediadas por REA, são apostas contemporâneas no sentido de potencializar a inovação, no design pedagógico dos cursos, com a peculiaridade de forte presença dos professores e discentes na organização e estruturação dos conteúdos para discussão dos grupos universitários.

Nobre et al. (2015), mencionando Okada et al. (2014), explicam o Fluxo REA, conforme Figura 1. Fica evidenciado que, para construção da metodologia dos REA, demanda-se o concurso de sete fases, a saber: planejar, buscar, gravar, ordenar, criar, executar e compartilhar. 


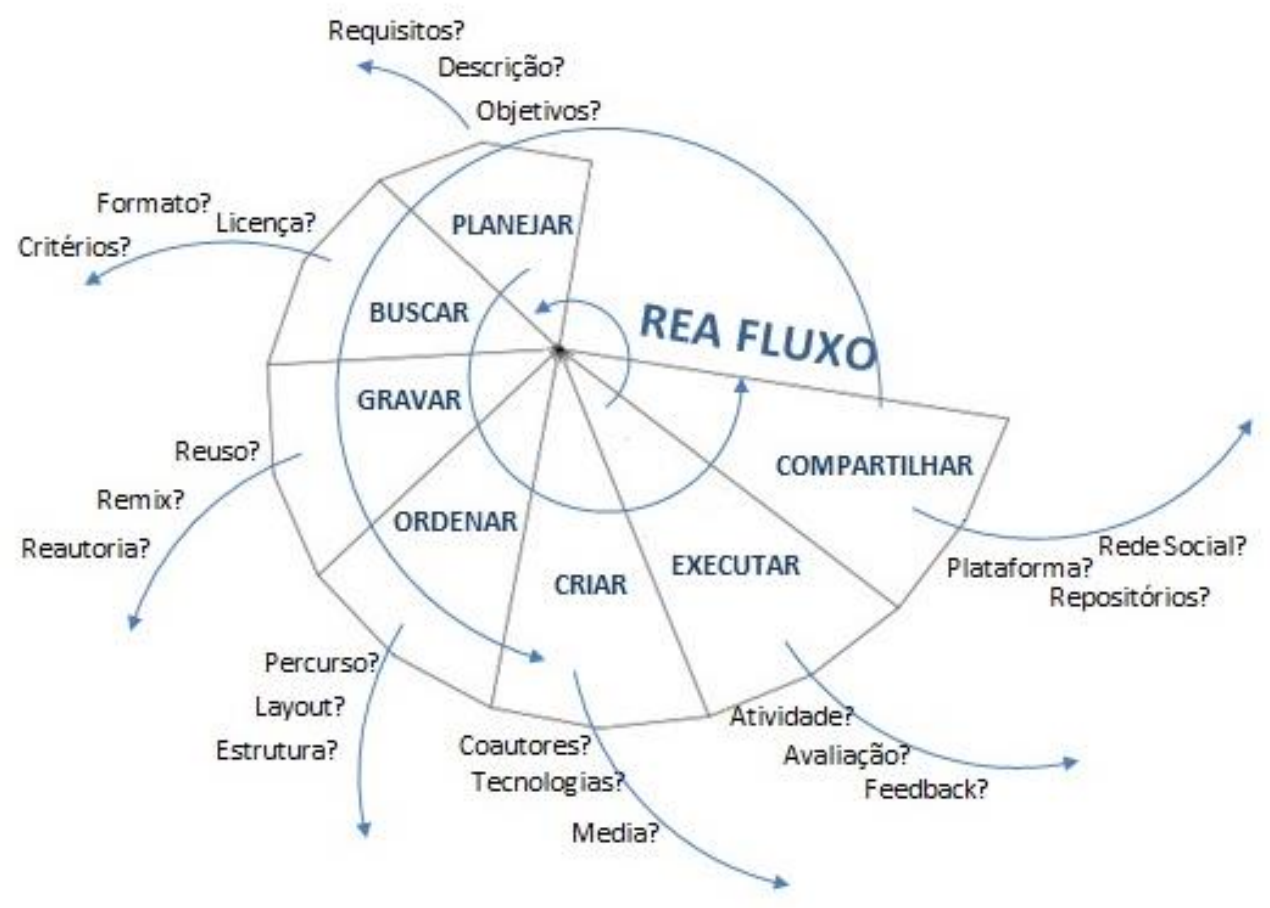

Figura 1: Fluxo REA

Fonte: OKADA et al., 2014, p. 7

Okada et al. (2014) propõem, ainda, que a disseminação do fluxo de elaboração e produção dos REA (fluxo REA) entre os participantes possibilita uma maior contribuição dos seus membros, na revisão e aperfeiçoamento da metodologia, como também da coautoria e da coaprendizagem.

Ainda na perspectiva de transformar os REA em uma inovação pedagógica, em plena utilização na formação e aprendizagem das pessoas, é importante trazer ao texto as reflexões e discussões apresentadas durante o curso de coaprendizagem na formação de gestores públicos, realizado em 2016, pela Open University ${ }^{9}$. Nas discussões, Okada (2016) apresenta algumas indagações sobre os REA e os objetivos do coaprendiz (Figura 2): Quais os objetivos do coaprendiz? Como os professores trabalham com currículo conteudista com o objetivo de preparar estudantes para exames e para o desenvolvimento de competências para a Educação do séc. XXI e habilidades da RRI? Por que usar gestão e tecnologias para pesquisar (GT)? Conforme, novamente, Okada (2016), esse mapa foi criado colaborativamente por oito participantes interessados na relação entre REA e RRI - Pesquisa e Inovação Responsáveis do

\footnotetext{
${ }^{9}$ Disponível em: <https://litemap.net/group.php?groupid=8831e766-382e-4e96-9e09-

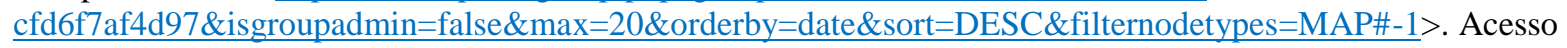
em: 20 abr. 2018.
} 
Programa de Pós-Graduação em Educação: Currículo

inglês Responsible Research and Innovation, que é uma abordagem criada pela Comissão Europeia com o objetivo de promover maior participação de diversos representantes da sociedade na construção do conhecimento. O projeto Engage, financiado pela Comissão Europeia, visa difundir o ensino e a aprendizagem da RRI, por meio da ciência e tecnologia com aprendizagem baseada em investigação (OKADA, 2016). Portanto,

[...] O currículo para RRI desenvolvido pelo projeto Engage apresenta uma estrutura que integra conhecimentos de ciência e habilidades de investigação científica, com atividades práticas baseadas em dilemas científicos para discussão, argumentação com base de jogos, resolução de problemas, desenvolvimento de projetos e avaliação da performance (TORRES et al., 2017, p. 1553).

O mapa da Figura 2 foi criado por oito representantes das áreas de RRI, gestão do conhecimento, educação superior, administração, tecnologia, com distintas atuações: professores, coordenadores pedagógicos, pesquisadores, gestores, tecnólogos e estudantes de graduação e pós-graduação. Okada (2014) também destaca o conceito de coaprendizagem como aprendizagem colaborativa aberta visando à coautoria de conhecimentos através dos REA e abordagens de RRI.

Fica evidenciado, em recortes das observações da autora, que a criação dos REA é complexa, tanto na compreensão dos seus conceitos como na utilização de tecnologias digitais que permitam ampliar as discussões em programas de formação ou na competência para a apropriação de tecnologias, metodologias, princípios e práticas para uma educação emancipadora, pelo desenvolvimento de competências essenciais relacionadas com a construção do conhecimento de forma colaborativa, visando às habilidades da RRI: elaborar perguntas; interrogar fontes; criticar afirmações; analisar dados; tirar conclusões; estimar riscos; analisar consequências; usar ética; justificar opiniões; comunicar ideias (OKADA, 2016). 
Programa de Pós-Graduação em Educação: Currículo

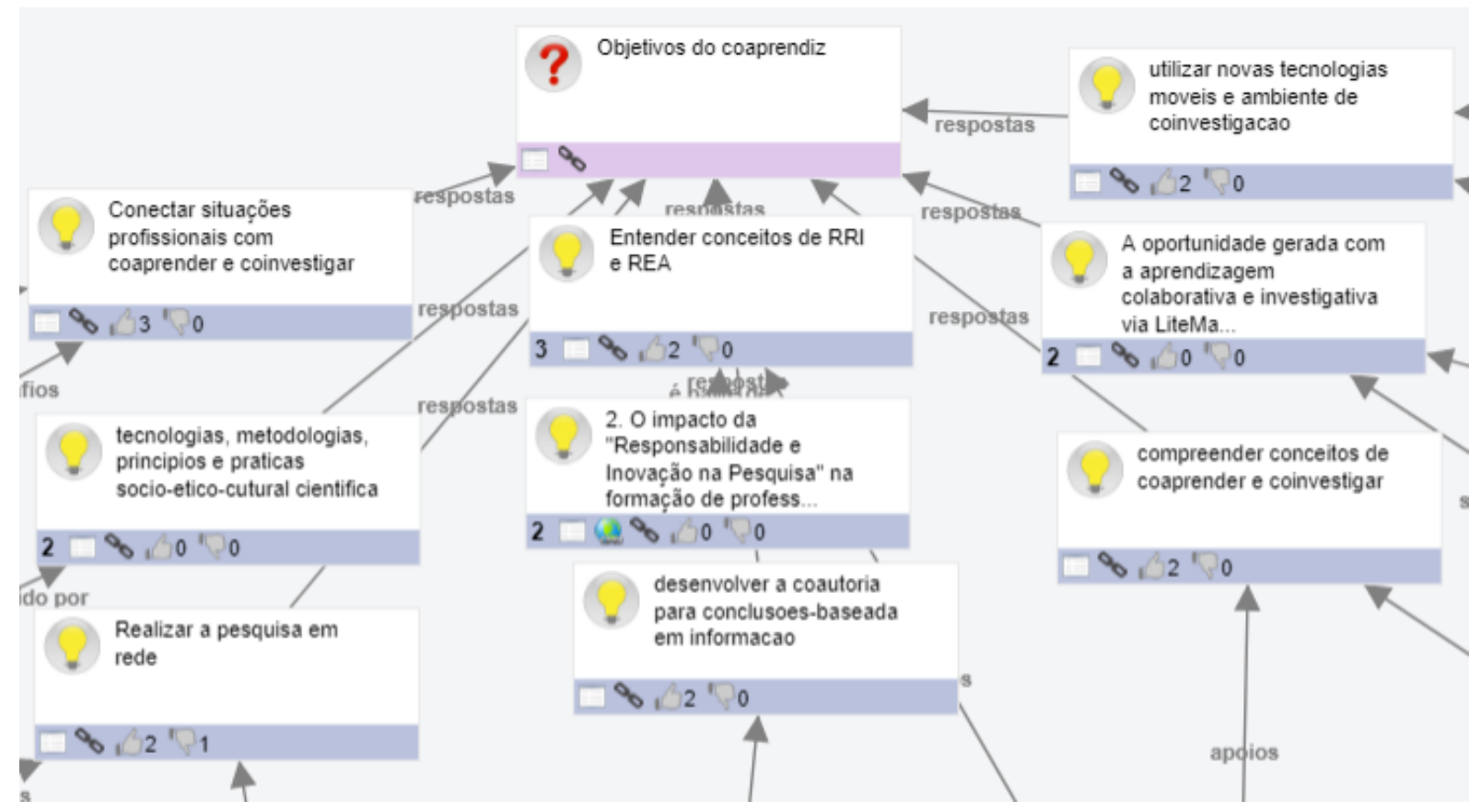

Figura 2: REA e objetivos da coaprendiz

Fonte: OKADA, 2016

Já Costa (2016), ao discutir sobre os conteúdos curriculares e a sua difusão em tecnologias digitais, apresenta algumas possibilidades relevantes: criar ambientes virtuais e plataformas de interação em rede; divulgar ações de pesquisa sobre cultura digital nos processos de comunicação; trabalhar com projetos; usar mapas conceituais, entre outros, conforme a Figura 3.

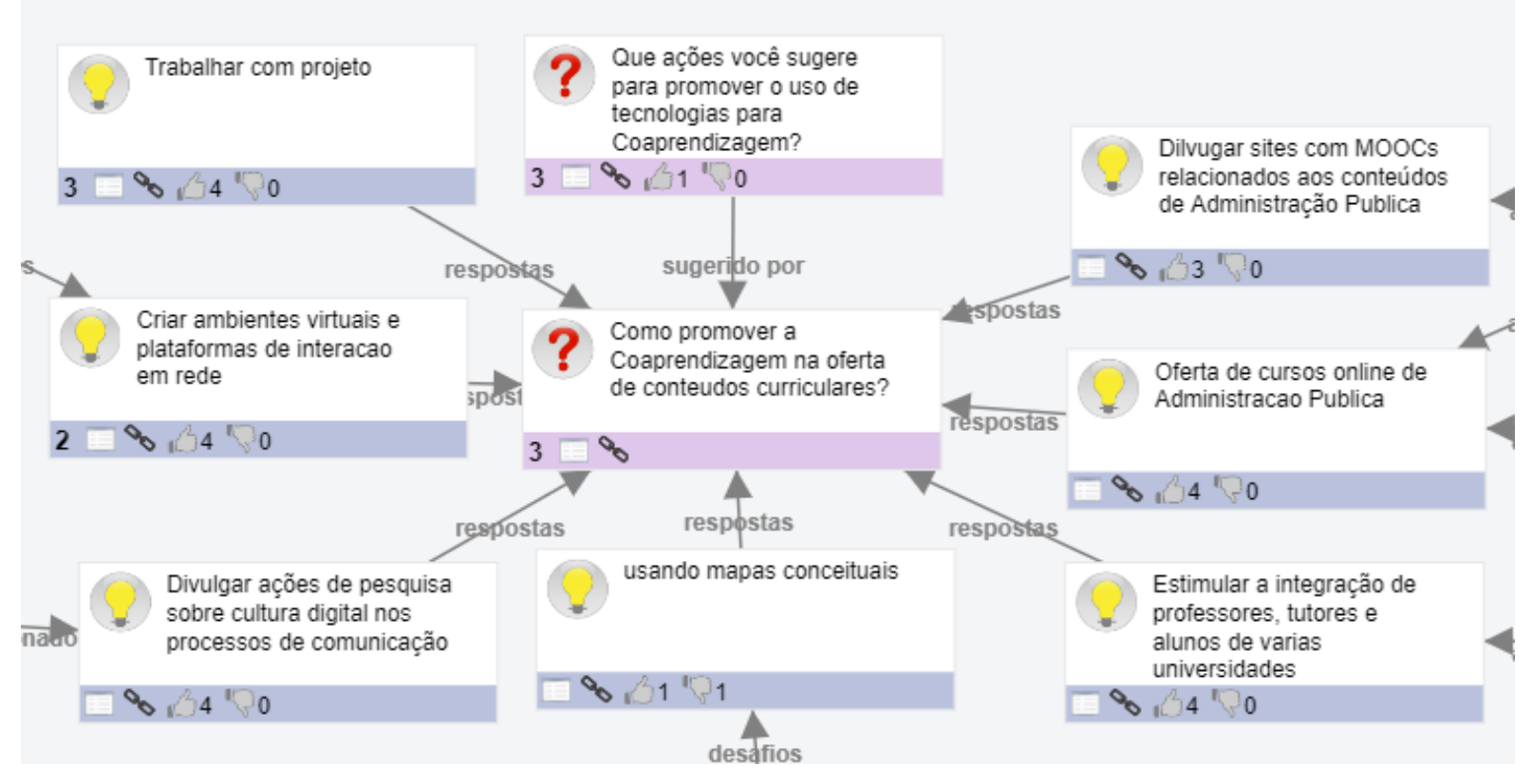

Figura 3: Conteúdos Curriculares e REA

Fonte: COSTA, 2016 
Sobre os Mapas Conceituais, recorremos a Okada (2014, p. 214) refletindo sobre o processo de construção de conhecimento mediado por REA, ao explicar por Novak $(1998)^{10}$, que são representações de "conceitos e suas relações mediante ligações hierárquicas descritas por palavras que estabelecem relações ou proposições válidas para compreensão de significados dentro de certo domínio de conhecimento". Cabe ressaltar que, em termos de Cartografia Cognitiva, o mapeamento pode ser desenvolvido com diferentes objetivos, como conceitual, mental, argumentativo e dialógico (OKADA, 2014).

Realizadas, neste primeiro momento, as abordagens teóricas, cabe, agora, descrever o caso do Mestrado Profissional em Gestão e Avaliação da Educação Pública na utilização experimental de REA e de mapeamentos cognitivos em uma disciplina obrigatória e na estruturação da Qualificação de seus mestrandos.

\section{A PROPOSTA DO MESTRADO PROFISSIONAL EM GESTÃo E AVALIAÇÃO DA EDUCAÇÃO PÚBLICA}

A experiência do Programa de Mestrado Profissional em Gestão e Avaliação da Educação Pública será apresentada aqui para que as Práticas Educacionais Abertas que serão analisadas de forma aprofundada sejam conhecidas em seu contexto e com todas as suas potencialidades.

O caráter inovador da proposta do Mestrado Profissional se evidencia inicialmente no fato de ele ter sido o primeiro mestrado profissional aprovado pela Capes na área de Educação, no ano de 2010. Mais além, de maneira a atender à demanda de alunos de várias partes do país, o seu formato semipresencial é único ainda hoje entre os 44 mestrados profissionais em educação avaliados pela Capes em 2017.

A gênese do Mestrado Profissional foi no Centro de Políticas Públicas e Avaliação da Educação(Caed) ${ }^{11}$, que, há mais de dez anos, se dedica a aproximar a Universidade Pública Federal e outras Instituições de Ensino Superior (IES) das redes públicas de ensino de educação básica, buscando garantir a qualidade da educação ofertada. Em função desse

\footnotetext{
${ }^{10}$ NOVAK, Joseph. Learning Creating and using Knowledge: concepts maps as facilitative tools in schools and corporations London Lawrence Erlbaum associates Mahwah, 1998.

${ }^{11}$ Conforme Sanabio, Marcos Tanure; Magaldi, Juliana Alves e Borges, Eliane Medeiros. TÃO LONGE E TÃO PERTO: um estudo de caso da utilização de TICs no Mestrado Profissional de Gestão e Avaliação da Educação Pública. Plurais Revista Multidisciplinar, v.2, n.1 (2017).
} 
Programa de Pós-Graduação em Educação: Currículo

diálogo já consolidado no campo da avaliação educacional, o Mestrado Profissional, já em sua primeira turma, contou com a parceria das redes estaduais de Minas Gerais, Rio de Janeiro e Ceará, além das redes municipais de Belo Horizonte e Juiz de Fora, do Ministério da Educação (MEC) e da Universidade Pública Federal. As vagas foram disputadas por gestores da educação básica atuantes nas escolas e nos órgãos regionais e centrais dessas redes, assim como técnicos do MEC e da Universidade. Participaram da seleção, também, profissionais que atuavam na Educação, mas que não se vinculavam a essas redes e que concorreram pelas vagas franqueadas.

Apresentaremos o cenário completo da distribuição nacional e internacional (em função da nossa parceira com Moçambique) das vagas do Mestrado Profissional nas suas oito turmas, pois acreditamos que a abrangência espacial desse mestrado profissional é um dos seus grandes desafios, conforme disposto na Tabela 1 .

Tabela 1: Turmas ano - vagas por conveniados e percentuais

\begin{tabular}{|c|c|c|c|c|c|c|c|c|c|c|c|}
\hline Instituições & & Convênios & 2010 & 2011 & 2012 & 2013 & 2014 & 2015 & 2016 & 2017 & Total \\
\hline \multirow{9}{*}{ Estaduais } & 1 & SEDUC/CE & 10 & 10 & 5 & 5 & 10 & & & 35 & 75 \\
\hline & 2 & SEE/AM & & & & 50 & 59 & 50 & & & 159 \\
\hline & 3 & SEEDUC/RJ & 20 & 21 & 22 & 20 & 7 & & & & 90 \\
\hline & 4 & SEE/AC & & & 5 & & & & & & 5 \\
\hline & 5 & SEDUC/MT & & & 5 & & & & & & 5 \\
\hline & 6 & SEE/ MG & 30 & 31 & 30 & 21 & & 60 & 60 & 60 & 292 \\
\hline & 7 & SEE/PE & & & 20 & & & & & & 20 \\
\hline & 8 & SEDUC/BA & & & & 3 & & & & & 3 \\
\hline & 9 & SEDUC/RO & & & & & & & 25 & 3 & 28 \\
\hline Municipais & 9 & $\begin{array}{l}\text { SEMEC/ } \\
\text { Teresina }\end{array}$ & & & & & 3 & 1 & 2 & 3 & 9 \\
\hline
\end{tabular}




\begin{tabular}{|c|c|c|c|c|c|c|c|c|c|c|c|}
\hline & 10 & SMED/ BH & 10 & 10 & 10 & 10 & & & & & 40 \\
\hline & 11 & $\begin{array}{l}\text { SME/ } \\
\text { Limeira, SP }\end{array}$ & & 5 & 5 & & & & & & 10 \\
\hline & 12 & SME/Recife & & & & & 5 & 2 & & & 7 \\
\hline & 13 & $\mathrm{SME} / \mathrm{JF}$ & 12 & & 15 & & & & & & 27 \\
\hline \multirow{6}{*}{ Federais } & 14 & UFJF & 13 & 10 & 5 & 5 & 15 & 20 & 25 & 25 & 118 \\
\hline & 15 & UFV & & & & 5 & & & & & 5 \\
\hline & 16 & IFPR & & & & 9 & & & & & 9 \\
\hline & 17 & MEC & 5 & & & & & & & & 5 \\
\hline & 18 & INEP & & 10 & & & & & & & 10 \\
\hline & 19 & SETEC/MEC & & 10 & 10 & & & & & & 20 \\
\hline \multirow{2}{*}{ Internacionais } & 20 & $\begin{array}{l}\text { Governo de } \\
\text { Moçambique }\end{array}$ & & 9 & 1 & & & & & & 10 \\
\hline & 21 & $\begin{array}{l}\text { Governo de } \\
\text { Angola }\end{array}$ & & 1 & & & & & & & 1 \\
\hline \multirow[b]{2}{*}{ Instituições } & 22 & FADEPE & & & & 5 & 5 & 5 & 5 & 12 & 32 \\
\hline & 23 & $\begin{array}{l}\text { Instituto } \\
\text { Unibanco }\end{array}$ & & 5 & 5 & & & 1 & & & 11 \\
\hline \multirow[t]{2}{*}{ Franqueados } & 24 & Franqueadas & 23 & 20 & 2 & & 15 & & & & 60 \\
\hline & & Total & 123 & 142 & 140 & 133 & 119 & 139 & 117 & 138 & 1.051 \\
\hline
\end{tabular}

Fonte: SANABIO e MAGALDI, 2014 e 2015, informações atualizadas pelos autores.

O desafio da expansão territorial se relaciona à necessidade de estar em grande parte do processo trabalhando a distância com suporte tecnológico, bem como à de dar suporte a pesquisas que estão vinculadas aos problemas enfrentados pela educação básica e superior em distintos espaços.

A dissertação profissional desenvolvida no Mestrado Profissional tem uma proposta interventiva, buscando provocar o aluno no decorrer do curso a perceber a realidade conhecimento em políticas educacionais: o caso do mestrado profíssional em gestão e avaliação da educação pública da Universidade Federal de Juiz de Fora (UFJF) 
profissional em que está inserido de forma distinta da que percebia ao ingressar, devendo, neste sentido, propor mudanças para o seu aprimoramento. A estratégia utilizada para que o gestor/aluno alcance essa maturidade profissional é o método de caso. Tal método como ferramenta de ensino possibilita uma percepção mais apurada das questões e dos problemas enfrentados por ele no contexto de trabalho.

Esta proposta corrobora com os princípios da RRI segundo os quais a pesquisa e a inovação devem se alinhar com as necessidades e prioridades sociais locais do contexto dos coaprendizes-coinvestigadores e coautores do conhecimento produzido.

Na dissertação, o caso é a base para um debate no qual o sujeito é levado a se posicionar sobre um problema de gestão educacional que se desenrola em seu contexto profissional. Essa ferramenta possibilita ampla discussão entre alunos, professores e tutores, de modo que se estabeleçam relações entre a perspectiva teórica e a dimensão prática do caso analisado.

O resultado são casos empíricos, ricos em descrição e diagnóstico, que permitem análises teóricas e baseadas em outras experiências e que levam a uma proposição de intervenção na realidade pesquisada. A dissertação do Mestrado Profissional está desenhada em três momentos básicos representados por capítulos, o primeiro apresenta ao leitor o caso, ou seja, a realidade a ser estudada com o seu diferencial, problema empírico que será analisado, atores, contexto político-legislativo. O segundo é dedicado à análise do problema, esse é o espaço para o debate com a teoria especializada além da contraposição de experiências semelhantes em realidades distintas. $\mathrm{O}$ uso da teoria na nossa dissertação tem o objetivo de iluminar a busca por alternativas viáveis para a resolução de problemas frente aos quais os gestores educacionais se encontram. O terceiro capítulo se dedica à apresentação de um plano de intervenção que visa à resolução ou à diminuição do problema diagnosticado no primeiro capítulo.

O coaprendiz é conduzido, ao logo das disciplinas voltadas para escrita da dissertação, para se tornar autor do conhecimento. Desse modo, passa a desenvolver uma reflexão sobre o contexto empírico em que atua profissionalmente, extraindo daí o problema sobre o qual se debruçará na dissertação e que será a base do seu caso. Na disciplina Dissertação I, o coaprendiz deve trabalhar o seu olhar sobre esse contexto familiar, elaborando uma proposta da dissertação baseada no caso, no problema, nos objetivos e num percurso metodológico. Em Dissertação II,deverá desenvolver um texto contendo o capítulo 1, ou seja, o caso, e uma 
Programa de Pós-Graduação em Educação: Currículo

proposta de caminho de análise com um referencial teórico metodológico. Esse material é submetido a uma banca de qualificação, que ajudará a estabelecer o rumo final da dissertação. E, por fim, em Dissertação III, o aluno deve conduzir a sua pesquisa de campo, desenvolver as análises e elaborar uma proposta de intervenção.

\section{EXPERIÊNCIAS NO MESTRADO PROFISSIONAL}

Para contextualizar as experiências no Mestrado Profissional com a utilização de REA, selecionamos dois momentos: um na disciplina de Administração e Financiamento da Educação Pública, ocorrida no $2^{\circ}$ semestre de 2017 e nas qualificações, em janeiro de 2018.

A primeira utilização dos REA por Mapas Conceituais, via plataforma LiteMap ${ }^{12}$, no Mestrado Profissional, ocorre com a configuração do grupo Gestão e Avaliação da Educação Pública $^{13}$, na disciplina Administração e Financiamento da Educação Pública, cujo objetivo é discutir a evolução da Administração Pública na sociedade contemporânea, bem como os desafios associados às Finanças Públicas. A plataforma LiteMap foi criada na Open University a partir de conceitos da Cartografia Cognitiva, descrita como "estudo que reúne diversas técnicas e tecnologias de mapeamento para representação, visualização e construção de conhecimento" (OKADA, 2014, p. 214). Ela tanto pode ser trabalhada como ferramenta de construção de mapas conceituais como de mapas dialógicos, estes últimos entendidos como "Representação da discussão por meio de um conjunto de questões ou problemas, possíveis soluções, respostas, prós e contras, anotações, referências e conclusões ou decisões" (OKADA, 2014, p. 214). A plataforma, cujo uso pode ser adaptado para diferentes finalidades educativas, foi utilizada no projeto Europeu Engage com o objetivo de formar educadores para a pesquisa e a inovação responsáveis (RRI) através de três etapas: uso de REA, adaptação da prática pedagógica e transformação do ensino-aprendizagem com a criação de novos REA(mapas do LiteMap).

A disciplina em questão apresenta-se dividida em três partes. $\mathrm{Na}$ primeira, são abordados os modelos de administração pública (patrimonialismo; burocrático; gerencial; societal e social) e suas implicações na gestão pública.

\footnotetext{
${ }^{12}$ Disponível em <https://litemap.net/>. Acesso em: 24 abr. 2018.

${ }^{13}$ Disponível em: <https://litemap.net/group.php?groupid=a850fe57-f098-481f-a68105d4580c4fd7\&isgroupadmin=true \& $\max =20 \&$ orderby=date\&sort=DESC \&filternodetypes=MAP\#-1 $>$. Acesso em: 24 abr. 2018.
}

Eliane Medeiros BORGES, Marcos Tanure SANABIO, Juliana Alves Magaldi Recursos educacionais abertos (REA) com pesquisa e inovação responsáveis (RRI) para a produção de conhecimento em políticas educacionais: o caso do mestrado profissional em gestão e avaliação da educação pública da Universidade Federal de Juiz de Fora (UFJF) 
Na segunda parte da disciplina, são discutidos aspectos de Finanças Públicas envolvendo Gasto Público e Funções de Governo; o Financiamento do Gasto Público (sistema tributário e transferências intergovernamentais no sistema federativo brasileiro); finanças da União, Estados e Municípios (características da estrutura de financiamento e evolução recente); Sistema de Planejamento e Orçamento no Brasil (fundamentos legais, conceitos básicos do sistema de planejamento, Ciclo Orçamentário no Brasil, gestão por programas, integração de planejamento e orçamento, eficiência do gasto público e custos); Execução Orçamentária (normas legais para o acompanhamento do gasto público) e Lei de responsabilidade fiscal (diretrizes sobre planejamento, transparência, prestação de contas, controle interno e externo e responsabilização).

$\mathrm{Na}$ terceira e última parte da disciplina, é abordado o tema do Financiamento da Educação Pública no Brasil: evolução histórica; as mudanças após a Constituição de 1988; a estratégia de adoção de Fundos Orçamentários Especiais - Fundef e Fundeb; e as inovações do Plano de Desenvolvimento da Educação (PDE) e seus impactos nas transferências voluntárias do Governo Federal (Plano de Metas e Plano de Ações Articuladas - PAR).

Especificamente, ao final da primeira parte, no conteúdo da disciplina, ministrada no $2^{\circ}$ semestre de 2017, no momento presencial, em fevereiro de 2018, com os mestrandos da Secretaria Estadual do Ceará -Seduc/CE, foi discutido o Estudo de Caso: A Diferença Está no Jeito de Fazer, elaborado por Eduardo de Lima Caldas e Patrícia Laczynski de Souza publicado na Revista Brasileira de Casos de Ensino em Administração, da Fundação Getúlio Vargas, no V. 7, n. 1- jan-jun 2017.

A sinopse do Caso relata que a Secretária de Educação de Vila Neblina, professora Gertrudes, visita duas Escolas Municipais de Ensino Fundamental, objetivando entender e compreender o processo da alimentação escolar, a merenda, a partir do recebimento dos ingredientes, alimentos in natura e alimentos processados, até a distribuição das refeições diariamente, passando pelo processo de definição das receitas e a produção propriamente dita. As visitas são conversas com as merendeiras: Dona Martésia e Dona Magali. A Dona Martésia da Escola Municipal de Ensino Fundamental (EMEF) Professor Asdrúbal José da Costa é uma servidora pública que vê dificuldades em tudo. Reclama da procedência dos gêneros alimentícios, da estocagem dos produtos, além de ser mal-humorada, indica que os gêneros estocados não dariam para mais de dez dias. 


\section{e-Curriculum}

Programa de Pós-Graduação em Educação: Currículo

Na outra visita, a professora Gertrudes entrevista a Dona Magali, da Escola Municipal de Ensino Fundamental Professor Petrônio Portela. Uma servidora tipicamente inovadora, que organizou a horta escolar auxiliada pela Diretora e por pais e moradores que conhecem o tema. Além, de incentivar a comunidade escolar (pais, professores, técnicos) depositarem em uma grande cesta de vime na entrada da escola, verduras, legumes e frutas para reforço da merenda. Também para evitar desperdícios, passa todos os dias em todas as salas para anotar a quantidade de alunos que irão almoçar. Enfim, duas merendeiras, duas posições dicotômicas e polares no trato da merenda escolar.

A atividade avaliativa foi, a partir do Caso de Ensino A Diferença Está no Jeito de Fazer, elaborar um Mapa Conceitual identificando: (I) a situação-problema; (II) as ideias para resolver a situação-problema; (III) os argumentos favoráveis; e (IV) os argumentos desfavoráveis. Cada um dos 35 mestrandos elaborou o seu Mapa Conceitual na plataforma do LiteMap, que foi disponibilizado para consulta e discussão. A Figura 4 apresenta uma imagem do site com o grupo Gestão e Avaliação da Educação Pública, com os Mapas Conceituais.

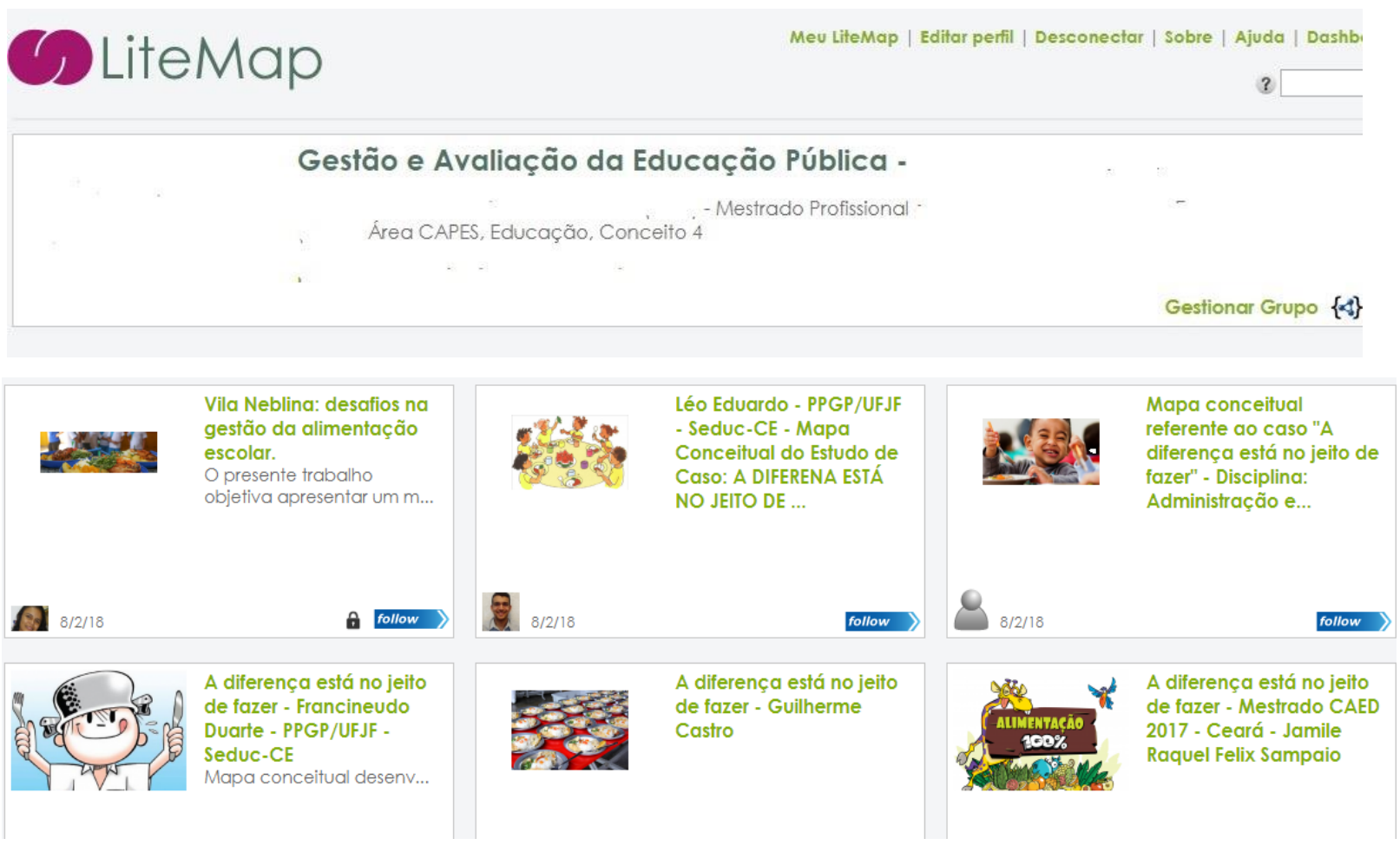

Figura 4: Gestão e Avaliação da Educação Pública, Mapas Conceituais Fonte: LITEMAP, 2018. 
Programa de Pós-Graduação em Educação: Currículo

De modo a explicitar a metodologia, na Figura 5, é demonstrado o Mapa Conceitual, com os componentes solicitados.

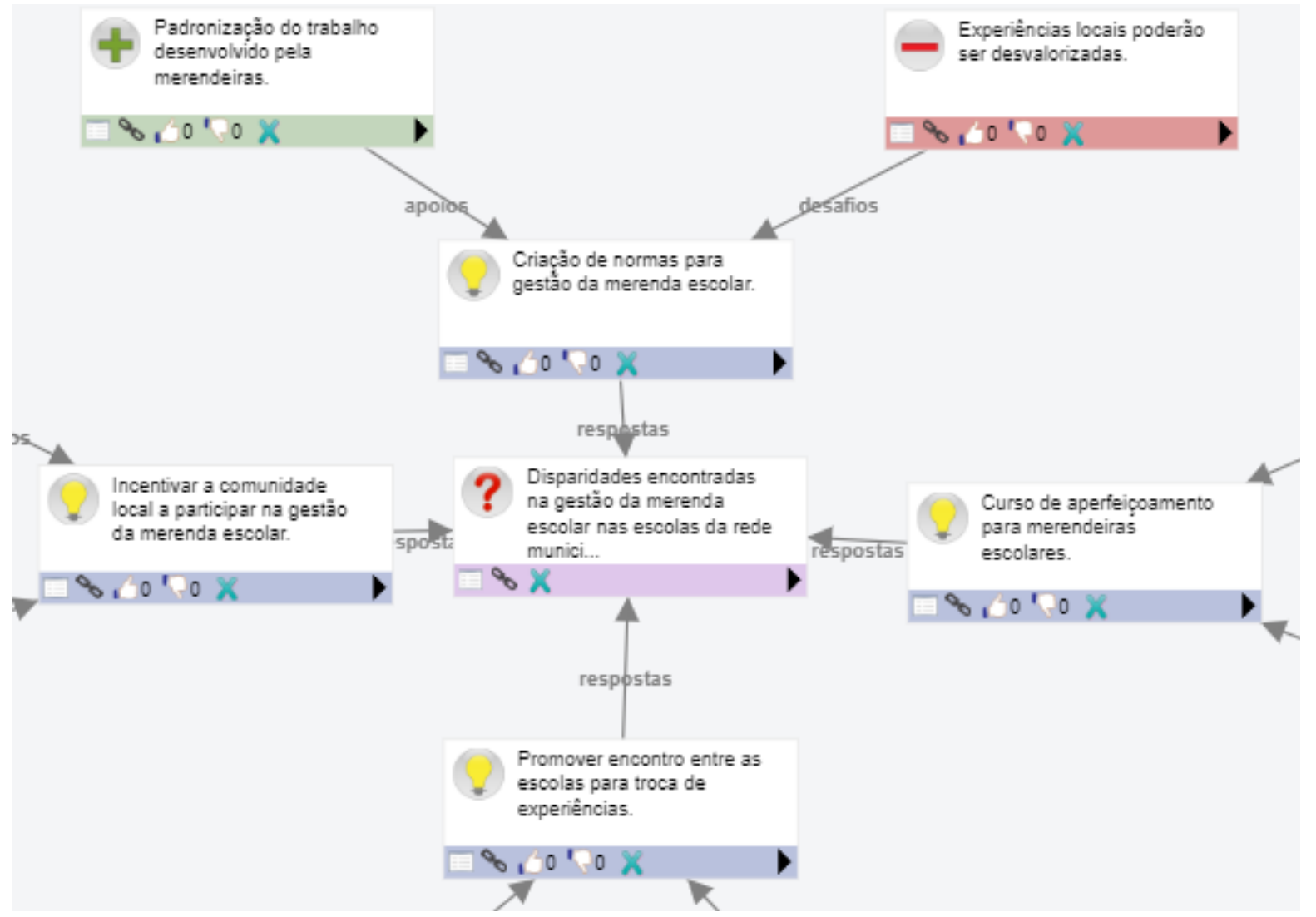

Figura 5: Mapa Conceitual

Fonte: LITEMAP, $2018^{14}$

No Quadro 2, a seguir, são detalhados os elementos solicitados, identificando uma lógica na análise do Caso de Ensino disponibilizado.

Quadro 2: Detalhamento do Mapa Conceitual

\begin{tabular}{|l|l|l|l|}
\hline Situação-Problema & $\begin{array}{l}\text { Ideias para resolver a } \\
\text { situação-problema }\end{array}$ & Argumentos favoráveis & \multicolumn{1}{|c|}{$\begin{array}{c}\text { Argumentos } \\
\text { desfavoráveis }\end{array}$} \\
\hline & $\begin{array}{l}\text { Criar normas para } \\
\text { gestão da merenda } \\
\text { escolar. }\end{array}$ & $\begin{array}{l}\text { Padronização do trabalho } \\
\text { desenvolvido pelas } \\
\text { merendeiras. }\end{array}$ & $\begin{array}{l}\text { Experiências locais } \\
\text { poderão } \\
\text { desvalorizadas. r r }\end{array}$ \\
\hline
\end{tabular}

\footnotetext{
${ }^{14}$ Disponível em <https://litemap.net/map.php?id=8e0de608-a386-4256-a314-79dcd5f75f31>. Acesso em: 26 abr. 2018.
} 


\begin{tabular}{|c|c|c|c|}
\hline \multirow[t]{3}{*}{$\begin{array}{c}\text { Disparidades } \\
\text { encontradas na gestão } \\
\text { da merenda escolar } \\
\text { nas escolas da rede } \\
\text { municipal de Vila } \\
\text { Neblina. }\end{array}$} & $\begin{array}{l}\text { Promover curso de } \\
\text { aperfeiçoamento para } \\
\text { merendeiras escolares. }\end{array}$ & $\begin{array}{l}\text { Merendeiras capacitadas } \\
\text { para o gerenciamento da } \\
\text { merenda escolar. }\end{array}$ & $\begin{array}{l}\text { Resistência } \\
\text { merendeiras } \\
\text { participar } \\
\text { formações. }\end{array}$ \\
\hline & $\begin{array}{l}\text { Promover encontro } \\
\text { entre as escolas para } \\
\text { troca de experiências. }\end{array}$ & $\begin{array}{ll}\text { Compartilhamento de } \\
\text { boas práticas entre as } \\
\text { escolas da rede. }\end{array}$ & $\begin{array}{l}\text { Diferenças } \quad \text { nos } \\
\text { contextos poderão } \\
\text { atrapalhar a adoção das } \\
\text { boas práticas. }\end{array}$ \\
\hline & $\begin{array}{l}\text { Incentivar } \\
\text { comunidade local a } \\
\text { participar na gestão da } \\
\text { merenda escolar. }\end{array}$ & $\begin{array}{ll}\text { Gestão democrática } & \text { no } \\
\text { acompanhamento } & \text { da } \\
\text { merenda escolar. } & \end{array}$ & $\begin{array}{l}\text { Ausência da família na } \\
\text { escola }\end{array}$ \\
\hline
\end{tabular}

Fonte: LITEMAP, $2018^{15}$

A outra experiência no Mestrado Profissional na utilização de REAs e Cartografia Cognitiva (LiteMap) se deu em quatro Qualificações, ocorridas em janeiro de 2018, nas quais foram ocultados os nomes dos mestrandos, sendo estas:

(I) Mestrando 1 - A implementação de um programa de pós-graduação na modalidade associativa: O caso do PMBqBM na UFJF/GV - Qualificação 09.01.18

(II) Mestrando 2- O fluxo de processos na Diretoria de Pessoal da Superintendência Regional de Monte Carmelo/MG: Um estudo de otimização.- Qualificação 09.01.18

(III) Mestrando 3- Procedimentos para aperfeiçoamento dos concursos públicos para docentes: O caso da UFJF - Qualificação em 16.01.18

(IV) Mestrando 4- Gestão da informação no setor de Gestão de Pessoas na Superintendência Regional de Ensino de São João Del-Rei/MG - Qualificação em 16.01.2018

A Qualificação no Mestrado Profissional se dá ao final da disciplina Dissertação II, quando o mestrando completa 18 meses de curso. A Qualificação é avaliada por uma banca composta de três docentes, sendo o Orientador, um membro do quadro permanente ou colaborador do Mestrado Profissional e um docente externo ao programa. O texto da Qualificação deverá apresentar a introdução, compondo uma contextualização, justificativa, questão ou pergunta da dissertação, objetivo geral, objetivos específicos e estrutura do

\footnotetext{
${ }^{15}$ Disponível em: <https://litemap.net/map.php?id=8e0de608-a386-4256-a314-79dcd5f75f31>. Acesso em: 22 abr. 2018.
} 
Programa de Pós-Graduação em Educação: Currículo

trabalho. O capítulo 1 apresenta o caso de gestão objeto da futura dissertação, com evidências. No capítulo 2, é apresentado o referencial teórico na sua totalidade ou parcialmente e a metodologia do trabalho.

A elaboração do Mapa Conceitual permite ao mestrando, ao orientador e aos membros da banca de Qualificação uma análise do trabalho como um todo e uma construção coletiva das evidências e melhorias necessárias ao trabalho, visando a sua continuação até a elaboração final da dissertação.

Os mapas do aplicativo LiteMap são de acesso aberto e tornam-se REA em contextos de pesquisa, formação, ensino e coaprendizagem. Esse processo consubstancia-se com os seis componentes-chave da RRI: abertura, participação pública, diversidade de gênero, governança/gestão, ética e educação científica (EC, 2018);

Por exemplo, na Qualificação de Corrêa (2018), intitulada de Gestão da informação no setor de Gestão de Pessoas na Superintendência Regional de Ensino de São João DelRei,fica evidenciada a questão da dissertação, compreendida como: Quais as ações podem ser implementadas para melhoria do fluxo de informações no Setor de Gestão de Pessoas da Diretoria de Pessoal na Superintendência Regional de Ensino de São João Del-Rei/MG? e as suas interferências ocasionadas pela falta de pessoal, instrumentos de informações precários, acúmulo de trabalho dos servidores do setor e muitas atribuições sob a responsabilidade do setor, conforme Figura 6:

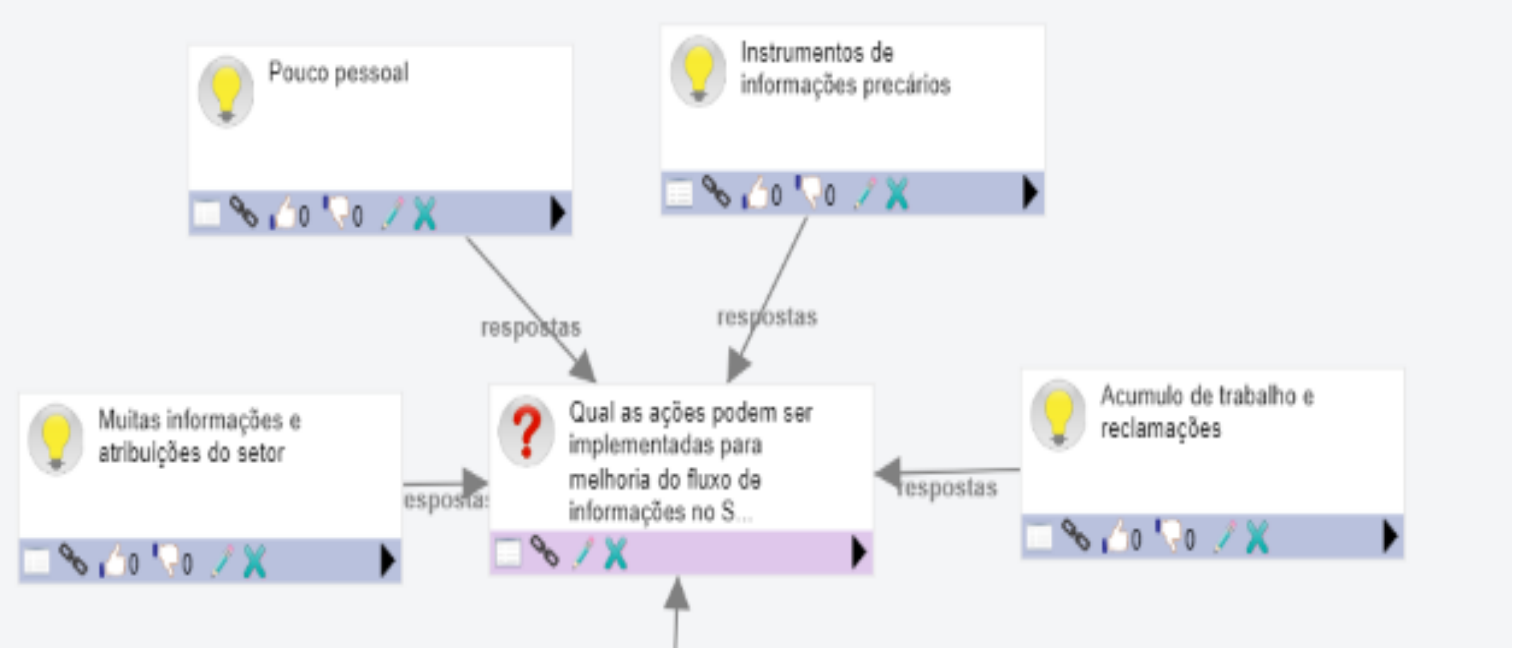

Figura 6: Questão ou problema da dissertação Fonte: LITEMAP, $2018^{16}$.

\footnotetext{
${ }^{16}$ Disponível em: <https://litemap.net/explore.php?groupid=a850fe57-f098-481f-a68105d4580c4fd7\&id=ddb58933-fbbd-4c16-9106-5cd90bc693d3 > . Acesso em: 26 abr. 2018.
} 


\section{$e$-Curriculum}

Programa de Pós-Graduação em Educação: Currículo

Tais constatações permitem uma sistematização do trabalho, além das análises sobre o Capítulo 1 - Estudo do Caso e sua estrutura textual, com as indicações de melhoria no texto, constantes da Figura 7:

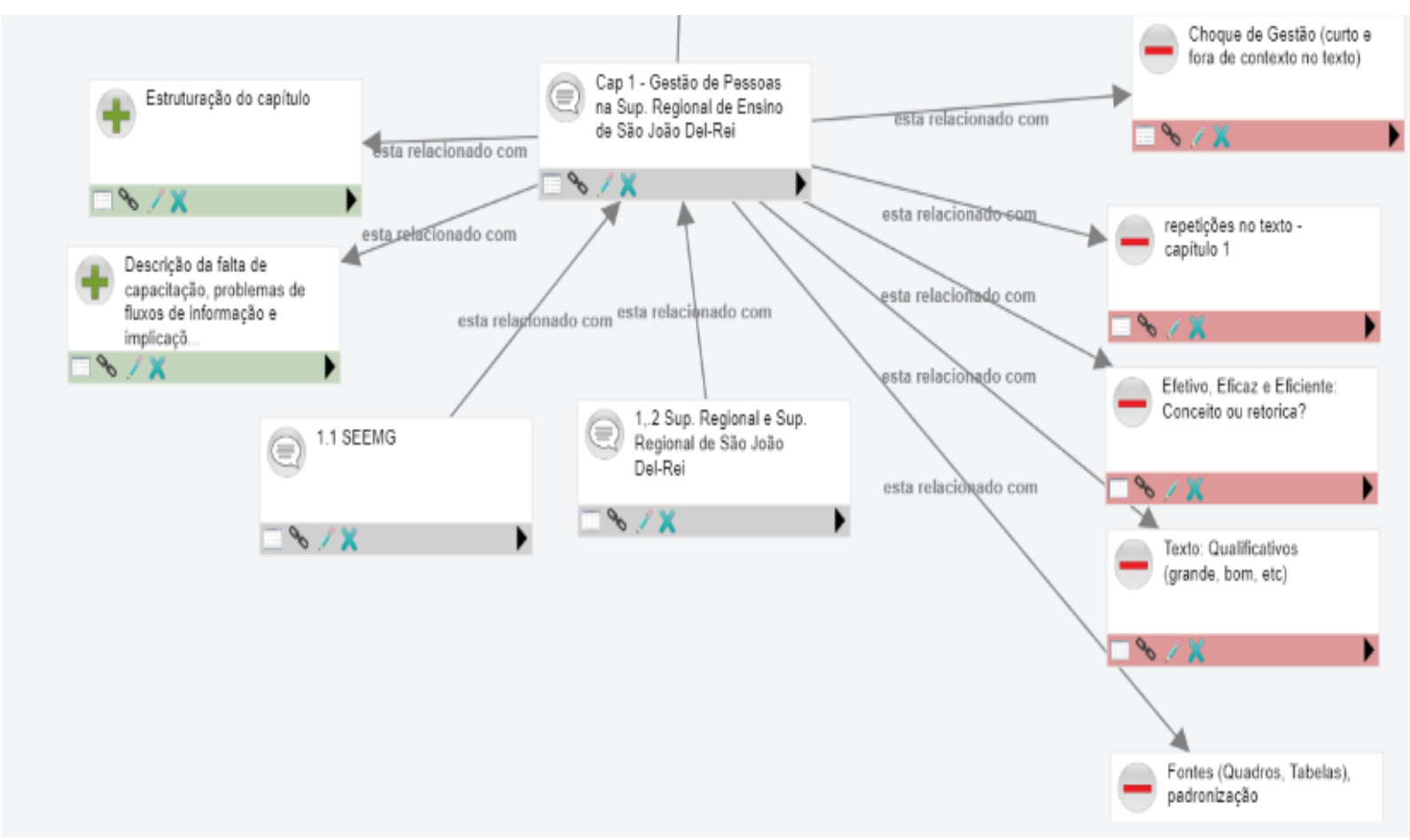

Figura 7: Capítulo 1- Gestão de Pessoas na Superintendência Regional de Ensino de São João Del-Rei.

Fonte: LITEMAP, $2018^{17}$

Além disso, foram feitas as observações sobre o Capítulo 2, intitulado de $\mathbf{O}$ papel da gestão da informação no atendimento ao público, em que foram abordados aspectos teóricos sobre gestão pública, gestão de pessoas e gestão da informação.

$\mathrm{Na}$ discussão da metodologia, são abordados os principais elementos, como: uma pesquisa de cunho qualitativa, em estudo de caso, com pesquisa documental, bibliográfica e de observação. Ainda, os sujeitos da pesquisa e os instrumentos (questionários e entrevistas semiestruturadas). Poderão ser observadas no Mapa Conceitual indicações dos presentes na Qualificação, das melhorias no texto, em todas as partes do trabalho, conforme apresentado na Figura 8:

\footnotetext{
${ }^{17}$ Disponível em: <https://litemap.net/explore.php?groupid=a850fe57-f098-481f-a68105d4580c4fd7\&id=ddb58933-fbbd-4c16-9106-5cd90bc693d3 > . Acesso em : 26 abr. 2018.
}

Eliane Medeiros BORGES, Marcos Tanure SANABIO, Juliana Alves Magaldi Recursos educacionais abertos (REA) com pesquisa e inovação responsáveis (RRI) para a produção de conhecimento em políticas educacionais: o caso do mestrado profissional em gestão e avaliação da educação pública da Universidade Federal de Juiz de Fora (UFJF) 


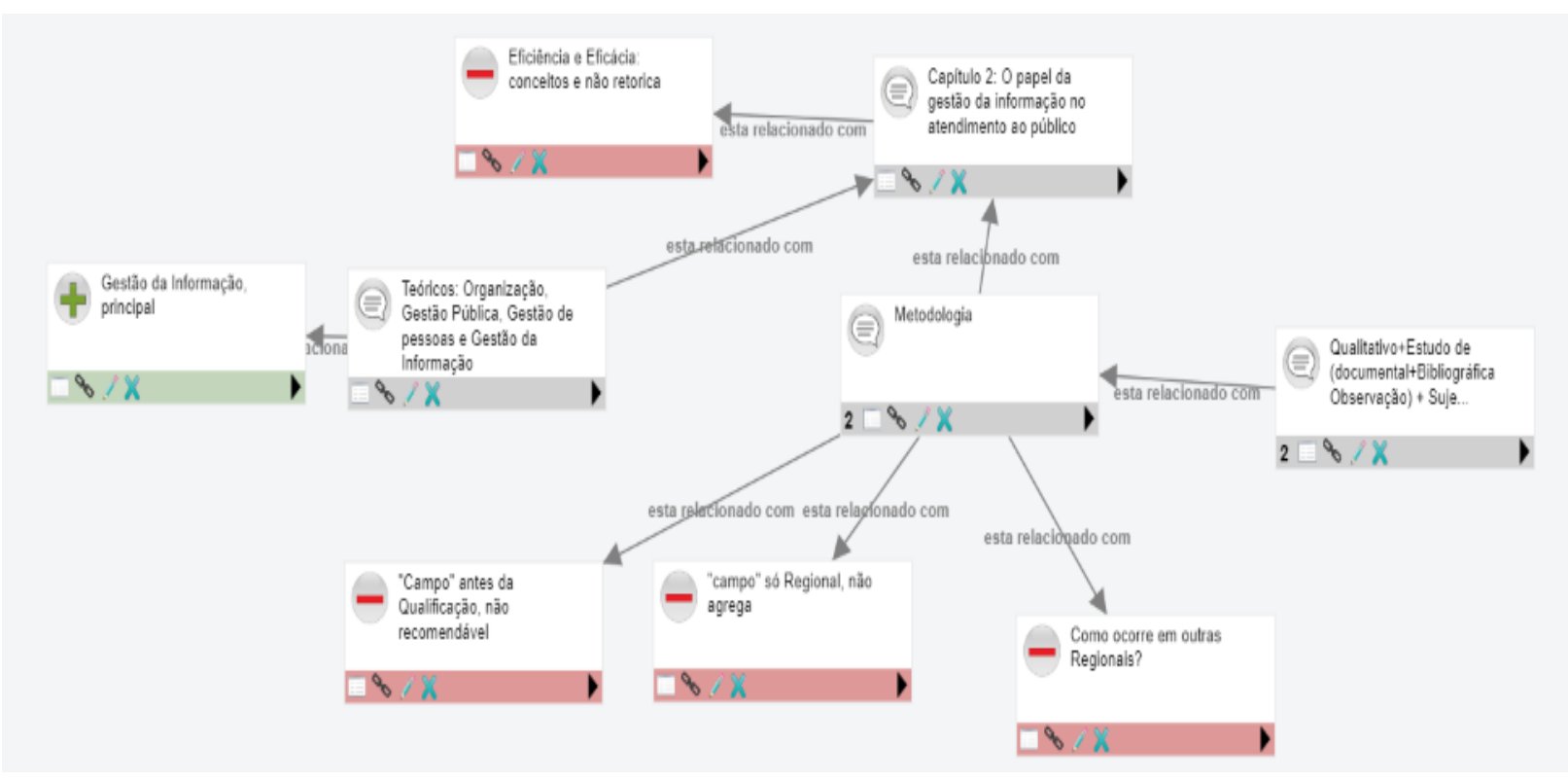

Figura 8: Capítulo 2 - O papel da gestão da informação no atendimento ao público e metodologia. Fonte: LITEMAP, $2018^{18}$

As experiências aqui relatadas desenvolvidas, de modo experimental, no Mestrado Profissional, a partir dos REA, em especial os Mapas Conceituais, foram exitosas e se demonstraram oportunas para sua disseminação em todo o Programa de Pós-Graduação. A análise do Estudo de Caso comprovou uma sistematização dos mestrandos sobre o objetoproblema da situação peculiar da produção de merenda escolar em um município hipotético. Além disso, a disponibilização das suas análises individuais em um ambiente aberto e de acesso livre suscitou debates e consultas posteriores. Vale destacar também que a autoria ficou preservada, com reconfigurações de abordagens para enfrentamento das discussões.

No que diz respeito à metodologia na análise da Qualificação, observamos um movimento de integração dos membros da banca, orientador, docente do Mestrado Profissional e membro externo, na interpretação de condicionantes do trabalho, que possibilitou interferências produtivas de melhoria do texto, visando à dissertação. Cabe destacar que a metodologia dos REA passou a ser utilizada por outros mestrandos para sistematização das suas qualificações, com acessos abertos e disponíveis nas contribuições e realinhamento dos textos.

\footnotetext{
${ }^{18}$ Disponível em: <https://litemap.net/explore.php?groupid=a850fe57-f098-481f-a68105d4580c4fd7 \&id=ddb58933-fbbd-4c16-9106-5cd90bc693d3 > . Acesso em: 26 abr. 2018.
} 


\section{CONSIDERAÇÕES FINAIS}

É consenso que vivemos em um contexto de mudanças rápidas e inovações tecnológicas produzidas contínua e incansavelmente, com importantes impactos nas sociedades. Esse contexto requer o alinhamento da pesquisa e da inovação com as necessidades e prioridades da sociedade conforme a abordagem RRI. No bojo desse processo, parece-nos oportuno e necessário que o campo da Educação não seja omisso diante das potencialidades pedagógicas dessas tecnologias. As possibilidades de interatividade, comunicação diferida ou assíncrona, ou em tempo real, acesso pleno e democrático à informação, efetivados por meio das TIC da era digital, não podem ser negligenciadas ou obliteradas pelas instituições responsáveis pela formação humana, formal ou informalmente.

Pensamos que esses novos meios ou dispositivos devem ser integrados aos processos pedagógicos em toda a sua potencialidade. Para isso, necessário se faz ampliar seu uso e experimentação, de modo que eles façam parte de processos mais amplos, que integrem diversas formas de ensinar e de aprender.

Acreditamos que essa apropriação, no entanto, não será feita sem desafios. Faz-se necessário que sejam articulados os modos objetivos, mais próprios da técnica, com uma dimensão mais humanística da Educação, de maneira a se obter resultados que sejam mais adequados às demandas de construção coletiva e interpessoais do conhecimento, atributos inerentes aos processos formativos e que se tornam ainda mais urgentes em sua atualidade na era pós-industrial.

Na reflexão abaixo, de Belloni, ao tratar da Educação a Distância, fortemente hoje ancorada no uso de tecnologias, está expresso parte deste dilema:

[...] sendo a principal função da EaD facilitar a aprendizagem a distância, é fundamental prover os estudantes de meios que permitam relações pessoais, embora não contíguas, e a oportunidade de discussão, o que exige a escolha de meios não apenas em virtude de suas potencialidades puramente técnicas, mas em função dos objetivos e de sua acessibilidade aos estudantes...vão além,, propondo que a educacão aberta e a distância deva basear-se no diálogo e na pesquisa, o que implica uma filosofia da educação que seja centrada no estudante e reconheça sua autonomia. [...] O diálogo deve ser estimulado não apenas entre os professores e estudantes, mas entre os próprios estudantes (através de grupos de estudo, grupos tutoriais...) e entre eles e os contextos sociais onde vivem e trabalham (BELLONI, 2009, p. 48).

O sentido de pesquisa, bem como o diálogo que propicia a interação, pode e deve estar presentecom foco na utilização de REA para novas coautorias. Como foi observado neste 
Programa de Pós-Graduação em Educação: Currículo

estudo, REA do LiteMap foram utilizados, adaptados e transformados num processo imbricado entre conhecimento mapeado nos mapas e prática transformada no processo de construir mapas. Parece-nos, como demonstrado no trabalho, que tais recursos se mostram muito viáveis nesse sentido, manifestando como seu significativo potencial o direcionamento para a argumentação, a evidência e a reflexão, como constituídos em elementos do processo científico de pesquisa, aqui aplicados ao ensino e à aprendizagem.

As demandas formativas com foco na pesquisa, portanto na compreensão freiriana de que "ensinar não é transferir conhecimento, mas criar as possibilidades para a sua produção ou a sua construção" (FREIRE, 2006, p.22), parecem estar disponibilizadas pela utilização metódica do recurso LiteMap.

A inovação possível nos processos de ensino e aprendizagem, as possibilidades de interação, interatividade e criatividade on-line, como características dos REA, associadas ao fato de sua disponibilização aberta e democrática, apontam maior exploração de seu uso, bem como compartilhamento de seus resultados. Considere-se, ainda, o uso viabilizado de múltiplas linguagens, produtos do processo de convergência nos dispositivos de comunicação digitais.

Nesse sentido, a experiência aqui descrita de sua aplicação na pós-graduação, no âmbito do Mestrado Profissional, revela-se como promissora. Ressaltamos, apenas, que se trata de novos desenvolvimentos no campo da Educação e, consequentemente, da exigência de novos estudos e experimentações. Pensamos, contudo, na necessidade a ser atendida no contexto de demandas contínuas e intensificadas de processos formativos em tempos de desterritorialização de saberes e territórios. Para todos os sujeitos envolvidos, há de produzirse uma Educação mais em consonância com os tempos digitais em que vivemos. 
Programa de Pós-Graduação em Educação: Currículo

\section{REFERÊNCIAS}

AMIEL, Tel. Educação aberta: configurando ambientes, práticas e recursos educacionais. In: Recursos Educacionais Abertos: práticas colaborativas políticas públicas. Salvador/Edufba, São Paulo/Casa da Cultura Digital, 2012. p. 17-33.

BELLONI, Maria Luiza. Educação a distância. Campinas, SP: Editores Associados, 2009.

BLIKSTEIN, Paulo.; ZUFFO, Marcelo Knörich. As sereias do ensino eletrônico. In.: SILVA, Marco (Org.). Educação online: teorias, práticas, legislação, formação coorporativa. São Paulo: Loyola, 2006.

CALDAS, Eduardo de Lima. SOUZA, Patrícia Laczsynski de. A diferença está no jeito de fazer. Revista Brasileira de Casos de Ensino em Administração. Fundação Getúlio Vargas, no. V. 7, n. 1- jan-jun 2017.

CASTELLS, Manuel. A sociedade em rede. A era da informação: economia, sociedade e cultura. Vol.1. São Paulo: Ed. Paz e Terra. 2005.

CORRÊA, Raquel Wilma. Gestão da informação no setor de Gestão de Pessoas na Superintendência Regional de Ensino de São João Del-Rei/MG. Qualificação do Programa de Mestrado Profissional em Gestão e Avaliação da Educação Pública. Mimeo, 2018.

COSTA, Alexandre Marino. Promover a Coaprendizagem nas disciplinas dos cursos: Coaprendizagem e RRI na gestão pública. Open University. 2016. Disponível em: <https://litemap.net/map.php?id=3e31d664-cca3-452d-b584-611dc9f044f8> . Acesso em: 22 abr. 2018.

EUROPEAN COMMISSION. RRI Responsible_research_innovation. Disponível em: $<$ https://ec.europa.eu/futurium/en/innovation4eu/terms/all/RRI\%20responsible_research_inno vation>. Acesso em: 02 abr. 2018.

FREIRE, Paulo. Pedagogia da autonomia: sabers necessários à Prática educativa. São Paulo: Paz e Terra, 2006.

NOBRE, Ana; MALLMANN, Elena Maria e MENDES, Antônio Quintas. A Universidade Aberta a caminho da inovação pedagógica: recursos e práticas educacionais abertas. Universidade Aberta de Portugal (2015). Disponível em:

<http://hdl.handle.net/10400.2/6885>. Acesso em: 22 abr. 2018.

OKADA, Alexandra. Colearn 2.0: refletindo sobre o conceito de coaprendizagem via REAs na web 2.0. Educação e tecnologias: reflexão, inovação e práticas, 7(1):1-15. 2011. Disponível em: 〈http://revistas.pucsp.br/index.php/curriculum/article/view/5813〉. Acesso em: 10 fev. 2018.

OKADA, Alexandra; MIKROYANNIDIS, Alexander; MEISTER , Izabel e LITTLE, Suzanne. Coaprendizagem através de REA e Mídias Sociais. Grupo KMi Tool-Libray. The

Eliane Medeiros BORGES, Marcos Tanure SANABIO, Juliana Alves Magaldi Recursos educacionais abertos (REA) com pesquisa e inovação responsáveis (RRI) para a produção de conhecimento em políticas educacionais: o caso do mestrado profissional em gestão e avaliação da educação pública da Universidade Federal de Juiz de Fora (UFJF) 
Programa de Pós-Graduação em Educação: Currículo

Open University -OU/UK. 2014. Disponível em:

<http://oer.kmi.open.ac.uk/?page id=4062>. Acesso em: 22 abr. 2018.

OKADA, Alexandra. Mapas do conhecimento com recursos educacionais abertos aplicados à coaprendizagem baseada em coinvestigação. In: TORRES, Patrícia ed. Complexidade:

Redes e Conexões na Produção do Conhecimento. Curitiba: SENAR - PR, pp. 213-237, 2014.

OKADA, Alexandra. Competências-chave para coaprender: fundamentos, metodologias e aplicações. Lisboa: WhiteBooks, 2014.

OKADA, Alexandra. Visão Geral: Coaprendizagem e RRI na gestão pública. Open University. 2016. Disponível em: <https://litemap.net/map.php?id=f3d0fe38-bd83-452fbd5e-ef9ac84bea5f>. Acesso em: 22 abr. 2018.

OKADA, Alexandra (Ed.). Engaging Science: Innovative Teaching for Responsible Citizenship. Milton Keynes: The Open University UK - Knowledge Media Institute. 2016. Disponível em: <http://oro.open.ac.uk/46456/1/Engage\%20COURSE\%20BOOK.pdf>. Acesso em: 19 ago. 2018.

OKADA, Alexandra. ENGAGE: Preparando a próxima geração para Responsabilidade Pesquisa e Inovação. Disponível em: 〈https://www.slideshare.net/alexandraokada/engagebrasil-2016>. Acesso em: 18 ago. 2018.

PEREIRA, Daniervelin Renata Marques; FETTERMANN, Joyce, Vieira e CESAR, Danilo Rodrigues. O que são recursos educacionais abertos? Limites e possibilidades em discursos. Calidoscópio Vol. 14, n. 3, p. 458-465, set/dez 2016.

PRETTO, Nelson. 2010. Redes colaborativas, ética hacker e educação. Educação em Revista, 26(3):305-316.

PETERS, Otto. Educação a distância em transição. São Leopoldo. Editora Unisinos, 2002.

SANABIO, Marcos Tanure; MAGALDI, Juliana Alves (Org.). Relatório Sucupira - 2013, Mestrado Profissional em Gestão e Avaliação da Educação Pública, Juiz de Fora, CAEd/UFxx, 2014.

SANABIO, Marcos Tanure; MAGALDI, Juliana Alves (Org.). Relatório Sucupira - 2014, Mestrado Profissional em Gestão e Avaliação da Educação Pública, Juiz de Fora, CAEd/UFxx, 2015.

SANABIO, Marcos Tanure; MAGALDI, Juliana Alves e BORGES, Eliane Medeiros. TÃO LONGE E TÃO PERTO: um estudo de caso da utilização de TICs no Mestrado Profissional de Gestão e Avaliação da Educação Pública. Plurais Revista Multidisciplinar, v.2, n.1 2017.

TORRES, Patrícia Lupion; SANTOS, Katia Ethiénne Esteves dos; KOWALSKI, Raquel Pasternak Glitz Kowalski e OKADA, Alexandra. Experiência de Educação Ambiental 


\section{$e$-Curriculum}

Programa de Pós-Graduação em Educação: Currículo

utilizando Pesquisa e Inovação Responsáveis da Pontifícia Universidade Católica do Paraná. Projeto Europeu. Rev. Diálogo Educ., Curitiba, v. 17, n. 55, p. 1530-1554, out./dez. 2017.

Eliane Medeiros BORGES, Marcos Tanure SANABIO, Juliana Alves Magaldi Recursos educacionais abertos (REA) com pesquisa e inovação responsáveis (RRI) para a produção de conhecimento em políticas educacionais: o caso do mestrado profissional em gestão e avaliação da educação pública da Universidade Federal de Juiz de Fora (UFJF) 